\title{
Mann iteration process for monotone nonexpansive mappings
}

\author{
Buthinah Abdullatif Bin Dehaish ${ }^{1 *}$ and Mohamed Amine Khamsi' ${ }^{2,3}$
}

\author{
"Correspondence: \\ bbindehaish@yahoo.com \\ ${ }^{1}$ Department of Mathematics, \\ Faculty of Science For Girls, King \\ Abdulaziz University, Jeddah, 21593, \\ Saudi Arabia \\ Full list of author information is \\ available at the end of the article
}

\begin{abstract}
Let $(X,\|\cdot\|)$ be a Banach space. Let $C$ be a nonempty, bounded, closed, and convex subset of $X$ and $T: C \rightarrow C$ be a monotone nonexpansive mapping. In this paper, it is shown that a technique of Mann which is defined by

$$
x_{n+1}=t_{n} T\left(x_{n}\right)+\left(1-t_{n}\right) x_{n}, \quad n=1,2, \ldots,
$$

is fruitful in finding a fixed point of monotone nonexpansive mappings.

MSC: Primary 06F30; 46B20; 47E10

Keywords: fixed point; Mann iteration process; nonexpansive mapping; uniformly convex Banach space; uniformly Lipschitzian mapping
\end{abstract}

\section{Introduction}

Nonexpansive mappings are those mappings which have Lipschitz constant equal to one. Their investigation remains a popular area of research in various fields. In 1965, Browder [1] and Göhde [2] independently proved that every nonexpansive self-mapping of a closed convex and bounded subset of a uniformly convex Banach space has a fixed point. This result was also obtained by Kirk [3] under slightly weaker assumptions. Since then several fixed point theorems for nonexpansive mappings in Banach spaces have been derived [4-6].

Recently a new direction has been developed when the Lipschitz condition is satisfied only for comparable elements in a partially ordered metric space. This direction was initiated by Ran and Reurings [7] (see also [8]) who proved an analogue of the classical Banach contraction principle [9] in partially ordered metric spaces. In both papers [7, 8], the motivation for this new direction is the problem of the existence of a solution which is positive. In other words, the classical approaches only deal with the existence of solutions, while here we ask whether a positive or negative solution exists. It is a natural question to ask since most of the classical metric spaces are endowed with a natural partial order.

When we relax the contraction condition to the case of the Lipschitz constant equal to 1, i.e., nonexpansive mapping, the completeness of the distance will not be enough as it was in the original case. We need some geometric assumptions to be added. But in general the Lipschitz condition on comparable elements is a weak assumption. In particular, we do not have the continuity property. Therefore, one has to be very careful when dealing with

(c) 2015 Bin Dehaish and Khamsi. This article is distributed under the terms of the Creative Commons Attribution 4.0 International License (http://creativecommons.org/licenses/by/4.0/), which permits unrestricted use, distribution, and reproduction in any medium, provided you give appropriate credit to the original author(s) and the source, provide a link to the Creative Commons license, and indicate if changes were made. 
such mappings. In this work we use the iterative methods [10] to prove the existence of fixed points of such mappings.

For more on metric fixed point theory, the reader may consult the books $[4,6]$.

\section{Basic definitions}

Let $(X,\|\cdot\|)$ be a Banach space endowed with a partial order $\leq$. As usual we adopt the convention $x \geq y$ if and only if $y \leq x$. Throughout, we assume that the order intervals are closed and convex. Recall that an order interval is any of the subsets

$$
[a, \rightarrow)=\{x \in X ; a \leq x\} \quad \text { or } \quad(\leftarrow, a]=\{x \in X ; x \leq a\}
$$

for any $a \in X$. As a direct consequence of this, the subset

$$
[a, b]=\{x \in X ; a \leq x \leq b\}=[a, \rightarrow) \cap(\leftarrow, b]
$$

is also closed and convex for any $a, b \in X$.

Next we give the definition of monotone mappings.

Definition 2.1 Let $(X,\|\cdot\|, \leq)$ be as above. Let $C$ be a nonempty subset of $X$. A map $T: C \rightarrow X$ is said to be

(a) monotone if $T(x) \leq T(y)$ whenever $x \leq y$;

(b) monotone $K$-Lipschitzian, $K \in \mathbb{R}^{+}$, if $T$ is monotone and

$$
\|T(x)-T(y)\| \leq K\|x-y\|
$$

whenever $x \leq y$. If $K=1$, then $T$ is said to be a monotone nonexpansive mapping. A point $x \in C$ is said to be a fixed point of $T$ if $T(x)=x$. The set of fixed points of $T$ is denoted by $\operatorname{Fix}(T)$.

Remark 2.1 It is not difficult to see that a monotone nonexpansive mapping may not be continuous. Therefore it is quite difficult to expect any nice behavior that will imply the existence of a fixed point.

Definition 2.2 Let $(X,\|\cdot\|)$ be a Banach space. Define the modulus of uniform convexity $\delta_{X}:(0,2] \rightarrow[0,1]$ by

$$
\delta_{X}(\varepsilon)=\inf \left\{1-\left\|\frac{x+y}{2}\right\| ;\|x\| \leq 1,\|x\| \leq 1 \text {, and }\|x-y\| \geq \varepsilon\right\} .
$$

Uniformly convex Banach spaces enjoy many nice geometric properties. The interested reader may consult the book [11].

\section{Iteration process for monotone nonexpansive mappings}

Let $(X,\|\cdot\|)$ be a Banach space.

Definition 3.1 [12-16] Let $C$ be a nonempty convex subset of a Banach space $(X,\|\cdot\|)$. Let $T: C \rightarrow C$ be a monotone mapping. Fix $x_{1} \in C$. The Mann iteration process is the 
sequence $\left\{x_{n}\right\}$ defined by

$$
x_{n+1}=t_{n} T\left(x_{n}\right)+\left(1-t_{n}\right) x_{n}
$$

for any $n \geq 1$, where $\left\{t_{n}\right\} \subset[0,1]$.

The following technical lemma will be useful to prove the main result of this work.

Lemma 3.1 Let $C$ be a nonempty closed convex subset of a Banach space $(X,\|\cdot\|)$. Let $T: C \rightarrow C$ be a monotone mapping. Fix $x_{1} \in C$ such that $x_{1} \leq T\left(x_{1}\right)$. Consider the Mann iteration sequence $\left\{x_{n}\right\}$ defined by (3.1). Then we have

$$
x_{n} \leq x_{n+1} \leq T\left(x_{n}\right)
$$

for any $n \geq 1$. Moreover, $\left\{x_{n}\right\}$ has at most one weak-cluster point. Hence if $C$ is weaklycompact, then $\left\{x_{n}\right\}$ is weakly convergent.

Proof We will prove (3.2) by induction. First note that if $c_{1}, c_{2} \in C$ are such that $c_{1} \leq c_{2}$, then $c_{1} \leq \alpha c_{1}+(1-\alpha) c_{2} \leq c_{2}$ holds for any $\alpha \in[0,1]$. This is true because order intervals are convex. This allows us to focus only on the proof of $x_{n} \leq T\left(x_{n}\right)$ for any $n \geq 1$. By assumption, we have $x_{1} \leq T\left(x_{1}\right)$, so the inequality is true for $n=1$. Assume that $x_{n} \leq T\left(x_{n}\right)$ for $n \geq 2$. Then we have

$$
x_{n} \leq t_{n} T\left(x_{n}\right)+\left(1-t_{n}\right) x_{n} \leq T\left(x_{n}\right)
$$

i.e., $x_{n} \leq x_{n+1} \leq T\left(x_{n}\right)$. Since $T$ is monotone, we get $T\left(x_{n}\right) \leq T\left(x_{n+1}\right)$. By transitivity of the order, we get $x_{n+1} \leq T\left(x_{n+1}\right)$. By induction, our inequality (3.2) is true for any $n \geq 1$. Next we look at the weak-cluster points of $\left\{x_{n}\right\}$. Let $\omega_{1}$ and $\omega_{2}$ be two weak-cluster points. Then there exist two subsequences $\left\{x_{\phi(n)}\right\}$ and $\left\{x_{\psi(n)}\right\}$ of $\left\{x_{n}\right\}$ such that

$$
\text { weak- } \lim _{n \rightarrow \infty} x_{\phi(n)}=\omega_{1} \quad \text { and } \quad \text { weak- } \lim _{n \rightarrow \infty} x_{\psi(n)}=\omega_{2}
$$

Fix $k \geq 1$. Since $\left\{x_{n}\right\}$ is monotone increasing and the order interval $\left[x_{k}, \rightarrow\right)$ is closed and convex, we conclude that $\omega_{i} \in\left[x_{k}, \rightarrow\right)$ for $i=1,2$. Hence $\left\{x_{n}\right\} \subset\left(\leftarrow, \omega_{i}\right]$ for $i=1,2$, holds which implies for the same reason $\omega_{j} \in\left(\leftarrow, \omega_{i}\right]$ for $i, j=1,2$. So we have $\omega_{1}=\omega_{2}$. Therefore $\left\{x_{n}\right\}$ has at most one weak-cluster point. Moreover, if we assume that $C$ is weakly compact, we conclude that $\left\{x_{n}\right\}$ is weakly convergent.

Remark 3.1 Under the assumptions of Lemma 3.1, if we assume that $T\left(x_{1}\right) \leq x_{1}$, we will show that

$$
T\left(x_{n}\right) \leq x_{n+1} \leq x_{n}
$$

for any $n \geq 1$. Moreover, the conclusions on the weak-cluster points of $\left\{x_{n}\right\}$ hold.

Lemma 3.2 Let $C$ be a nonempty, closed, and convex subset of a Banach space $(X,\|\cdot\|)$. Let $T: C \rightarrow C$ be a monotone nonexpansive mapping. Let $\left\{t_{n}\right\} \subset[0,1]$ be the sequence 
associated to the Mann iteration process defined by (3.1). Then, for any $\omega \in \operatorname{Fix}(T)$, $\lim _{n \rightarrow \infty}\left\|x_{n}-\omega\right\|$ exists provided $x_{1}$ and $\omega$ are comparable.

Proof Without loss of any generality, assume that $x_{1} \leq \omega$. Let us prove that $x_{n} \leq \omega$ for any $n \geq 1$. Since $T$ is monotone, then we must have $T\left(x_{1}\right) \leq T(\omega)=\omega$. Since the order interval $(\leftarrow, \omega]$ is convex, we conclude that $x_{2} \leq \omega$. Next we use the fact that $T$ is monotone to get $T\left(x_{2}\right) \leq T(\omega)=\omega$. And again, because of the convexity of $(\leftarrow, \omega]$, we get $x_{3} \leq \omega$. By induction we will show that $x_{n} \leq \omega$ for any $n \geq 1$, as claimed. Since $T$ is monotone nonexpansive, we get

$$
\left\|T\left(x_{n}\right)-\omega\right\|=\left\|T\left(x_{n}\right)-T(\omega)\right\| \leq\left\|x_{n}-\omega\right\|
$$

which implies

$$
\begin{aligned}
\left\|x_{n+1}-\omega\right\| & \leq t_{n}\left\|T\left(x_{n}\right)-\omega\right\|+\left(1-t_{n}\right)\left\|x_{n}-\omega\right\| \\
& \leq t_{n}\left\|x_{n}-\omega\right\|+\left(1-t_{n}\right)\left\|x_{n}-\omega\right\|=\left\|x_{n}-\omega\right\|
\end{aligned}
$$

for any $n \geq 1$. This means that $\left\{\left\|x_{n}-\omega\right\|\right\}$ is a decreasing sequence, which implies that $\lim _{n \rightarrow \infty}\left\|x_{n}-\omega\right\|$ exists.

In the general theory of nonexpansive mappings, the main property of the Mann iterative sequence is an approximate fixed point property. Recall that $\left\{x_{n}\right\}$ is called an approximate fixed point sequence of the mapping $T$ if $\lim _{n \rightarrow+\infty}\left\|x_{n}-T\left(x_{n}\right)\right\|=0$. We have a similar conclusion for monotone nonexpansive mappings if we assume that $X$ is uniformly convex.

Theorem 3.1 Let C be a nonempty, closed, convex and bounded subset of a Banach space $(X,\|\cdot\|)$. Let $T: C \rightarrow C$ be a monotone nonexpansive mapping. Assume that $X$ is uniformly convex, and there exist $\omega \in \operatorname{Fix}(T)$ and $x_{1} \in C$ such that $x_{1}$ and $\omega$ are comparable. Then we have

$$
\lim _{n \rightarrow \infty}\left\|x_{n}-T\left(x_{n}\right)\right\|=0
$$

where $\left\{x_{n}\right\}$ is the Mann iterative sequence generated by (3.1) which starts at $x_{1}$, with $t_{n} \in$ $[a, b]$ for some $a>0$ and $b<1$.

Proof Let $\omega \in \operatorname{Fix}(T)$. Let $x_{1} \in C$ be comparable to $\omega$. Using Lemma 3.2, we conclude that $\lim _{n \rightarrow \infty}\left\|x_{n}-\omega\right\|$ exists. Set $R=\lim _{n \rightarrow \infty}\left\|x_{n}-\omega\right\|$. Without loss of any generality, we may assume $R>0$. Moreover, we have

$$
\limsup _{n \rightarrow \infty}\left\|T\left(x_{n}\right)-\omega\right\|=\limsup _{n \rightarrow \infty}\left\|T\left(x_{n}\right)-T(\omega)\right\| \leq \limsup _{n \rightarrow \infty}\left\|x_{n}-\omega\right\|=R,
$$

since $x_{n}$ and $\omega$ are comparable, for any $n \geq 1$. On the other hand, we have

$$
\left\|x_{n+1}-\omega\right\| \leq t_{n}\left\|T\left(x_{n}\right)-\omega\right\|+\left(1-t_{n}\right)\left\|x_{n}-\omega\right\| \leq\left\|x_{n}-\omega\right\|
$$


for any $n \geq 1$. Let $\mathcal{U}$ be a nontrivial ultrafilter over $\mathbb{N}$. Then $\lim _{\mathcal{U}} t_{n}=t \in[a, b]$. Hence

$$
R=\lim _{\mathcal{U}}\left\|x_{n+1}-\omega\right\| \leq t \lim _{\mathcal{U}}\left\|T\left(x_{n}\right)-\omega\right\|+(1-t) R \leq R
$$

Since $t \neq 0$, we get $\lim _{\mathcal{U}}\left\|T\left(x_{n}\right)-\omega\right\|=R$. Consider the ultrapower $(X)_{\mathcal{U}}$ of $X$ (see [11]). Set $\tilde{x}=\left(\left\{x_{n}\right\}\right)_{\mathcal{U}}, \tilde{y}=\left(\left\{T\left(x_{n}\right)\right\}\right)_{\mathcal{U}}$ and $\tilde{\omega}=(\{\omega\})_{\mathcal{U}}$. Then we have

$$
\|\tilde{x}-\tilde{\omega}\|_{\mathcal{U}}=\|\tilde{y}-\tilde{\omega}\|_{\mathcal{U}}=\|t \tilde{x}+(1-t) \tilde{y}-\tilde{\omega}\|_{\mathcal{U}} .
$$

Since $t \in(0,1)$ and $X$ is uniformly convex, then $(X)_{\mathcal{U}}$ is strictly convex, which implies $\tilde{x}=\tilde{y}$, i.e., $\lim _{n, \mathcal{U}}\left\|x_{n}-T\left(x_{n}\right)\right\|=0$. Since $\mathcal{U}$ was an arbitrary nontrivial ultrafilter, we conclude that $\lim _{n \rightarrow \infty}\left\|x_{n}-T\left(x_{n}\right)\right\|=0$, which completes the proof of Theorem 3.1.

The conclusion of Theorem 3.1 is strongly dependent on the assumption that a fixed point of $T$ which is comparable to $x_{1}$ exists. In fact, we may relax such assumption and obtain a similar conclusion. First we will need the following technical lemma.

Lemma 3.3 Let $C$ be a nonempty convex subset of a Banach space $(X,\|\cdot\|)$. Let $T: C \rightarrow C$ be a monotone nonexpansive mapping. Let $x_{1} \in C$ be such that $x_{1}$ and $T\left(x_{1}\right)$ are comparable. Let $\left\{x_{n}\right\}$ be the Mann iterative sequence defined by (3.1) such that $\left\{t_{n}\right\} \subset[0,1)$. Then, for any $i, n \geq 1$, we have

$$
\begin{aligned}
\left(1+\sum_{s=i}^{i+n-1} t_{s}\right)\left\|x_{i}-T\left(x_{i}\right)\right\| \leq & \left\|T\left(x_{i+n}\right)-x_{i}\right\| \\
& +\prod_{s=i}^{i+n-1}\left(1-t_{s}\right)^{-1}\left[\left\|T\left(x_{i}\right)-x_{i}\right\|-\left\|T\left(x_{i+n}\right)-x_{i+n}\right\|\right] .
\end{aligned}
$$

Proof Without loss of any generality, we may assume $x_{1} \leq T\left(x_{1}\right)$. In this case, we have $x_{n} \leq$ $x_{n+1} \leq T\left(x_{n}\right) \leq T\left(x_{n+1}\right)$ for any $n \geq 1$. In particular, we have $\left\|T\left(x_{n+1}\right)-T\left(x_{n}\right)\right\| \leq\left\|x_{n+1}-x_{n}\right\|$ for any $n \geq 1$. Moreover, from the definition of $\left\{x_{n}\right\}$ we have $\left\|x_{n+1}-x_{n}\right\|=t_{n}\left\|x_{n}-T\left(x_{n}\right)\right\|$ for any $n \geq 1$. Therefore all the assumptions of Proposition 1 of [10] are satisfied, which implies the conclusion of Lemma 3.3.

Using this lemma, we have a similar conclusion to Theorem 3.1 with less stringent assumptions. This result is similar to the one found in [13].

Theorem 3.2 Let $C$ be a nonempty, closed, convex and bounded subset of a Banach space $(X,\|\cdot\|)$. Let $T: C \rightarrow C$ be a monotone nonexpansive mapping. Let $x_{1} \in C$ be such that $x_{1}$ and $T\left(x_{1}\right)$ are comparable. Let $\left\{x_{n}\right\}$ be the Mann iterative sequence defined by (3.1) such that $\left\{t_{n}\right\} \subset[a, b]$, with $a>0$ and $b<1$. Then we have $\lim _{n \rightarrow+\infty}\left\|x_{n}-T\left(x_{n}\right)\right\|=0$.

Proof First note that the sequence $\left\{\left\|x_{n}-T\left(x_{n}\right)\right\|\right\}$ is decreasing. Indeed, we have

$$
\begin{aligned}
\left\|x_{n+1}-T\left(x_{n+1}\right)\right\| & =\left\|\left(1-t_{n}\right) x_{n}+t_{n} T\left(x_{n}\right)-T\left(x_{n+1}\right)\right\| \\
& =\left\|\left(1-t_{n}\right)\left(x_{n}-T\left(x_{n}\right)\right)+T\left(x_{n}\right)-T\left(x_{n+1}\right)\right\|
\end{aligned}
$$




$$
\begin{aligned}
& \leq\left(1-t_{n}\right)\left\|x_{n}-T\left(x_{n}\right)\right\|+\left\|T\left(x_{n}\right)-T\left(x_{n+1}\right)\right\| \\
& \leq\left(1-t_{n}\right)\left\|x_{n}-T\left(x_{n}\right)\right\|+\left\|x_{n}-x_{n+1}\right\| \\
& =\left(1-t_{n}\right)\left\|x_{n}-T\left(x_{n}\right)\right\|+t_{n}\left\|x_{n}-T\left(x_{n}\right)\right\| \\
& =\left\|x_{n}-T\left(x_{n}\right)\right\|
\end{aligned}
$$

for any $n \geq 1$. Set $\lim _{n \rightarrow+\infty}\left\|x_{n}-T\left(x_{n}\right)\right\|=R$. If we let $i \rightarrow+\infty$ in the inequality obtained in Lemma 3.3, we get

$$
(1+n a) R \leq \delta(C)
$$

for any $n \geq 1$, where we used the facts

$$
(1+n a) \leq 1+\sum_{s=i}^{i+n-1} t_{s}, \quad \text { and } \quad\left\|T\left(x_{i+n}\right)-x_{i}\right\| \leq \delta(C)
$$

with $\delta(C)=\sup \{\|x-y\| ; x, y \in C\}<+\infty$. Hence

$$
R \leq \frac{\delta(C)}{(1+n a)}, \quad n \geq 1
$$

Clearly this will imply $R=0$, i.e., $\lim _{n \rightarrow+\infty}\left\|x_{n}-T\left(x_{n}\right)\right\|=0$.

Before we state the main fixed point result of this work, let us recall the definition of the weak-Opial condition.

Definition 3.2 [17] Let $(X,\|\cdot\|)$ be a Banach space. We will say that $X$ satisfies the weakOpial condition if for any sequence $\left\{y_{n}\right\}$ which converges weakly to $y$, we have

$$
\liminf _{n \rightarrow \infty}\left\|y_{n}-y\right\|<\liminf _{n \rightarrow \infty}\left\|y_{n}-z\right\|
$$

for any $z \in X$ such that $y \neq z$.

Theorem 3.3 Let $(X,\|\cdot\|)$ be a Banach space which satisfies the weak-Opial condition. Let $C$ be a nonempty weakly compact convex subset of $X$. Let $T: C \rightarrow C$ be a monotone nonexpansive mapping. Assume that there exists $x_{1} \in C$ such that $x_{1}$ and $T\left(x_{1}\right)$ are comparable. Let $\left\{x_{n}\right\}$ be the Mann iterative sequence defined by (3.1) such that $\left\{t_{n}\right\} \subset[a, b]$, with $a>0$ and $b<1$. Then $\left\{x_{n}\right\}$ is weakly convergent to $x$ which is a fixed point of $T$, i.e., $T(x)=x$. Moreover, $x$ and $x_{1}$ are comparable.

Proof Without loss of any generality, we may assume that $x_{1} \leq T\left(x_{1}\right)$. Lemma 3.1 implies that $\left\{x_{n}\right\}$ is weakly convergent to some $x \in C$ with $x_{n}$ and $x$ comparable for any $n \geq 1$. Assume to the contrary that $T(x) \neq x$. Since the assumptions of Theorem 3.2 are satisfied, then we must have $\lim _{n \rightarrow+\infty}\left\|x_{n}-T\left(x_{n}\right)\right\|=0$. Using the definition of the weak Opial condition, we get

$$
\liminf _{n \rightarrow \infty}\left\|x_{n}-x\right\|<\liminf _{n \rightarrow \infty}\left\|x_{n}-T(x)\right\|=\liminf _{n \rightarrow \infty}\left\|T\left(x_{n}\right)-T(x)\right\| \leq \liminf _{n \rightarrow \infty}\left\|x_{n}-x\right\| .
$$


This is a contradiction. Hence $T(x)=x$, i.e., $x$ is a fixed point of $T$. As we saw $x$ and $x_{1}$ are comparable, which completes the proof of Theorem 3.3.

\author{
Competing interests \\ The authors declare that they have no competing interests.
}

Authors' contributions

All authors contributed equally to the writing of this paper. All authors read and approved the manuscript.

\title{
Author details
}

'Department of Mathematics, Faculty of Science For Girls, King Abdulaziz University, Jeddah, 21593, Saudi Arabia. ${ }^{2}$ Department of Mathematical Sciences, The University of Texas at El Paso, El Paso, TX 79968, USA. ${ }^{3}$ Department of Mathematics \& Statistics, King Fahd University of Petroleum and Minerals, Dhahran, 31261, Saudi Arabia.

\section{Acknowledgements}

This work was funded by the Deanship of Scientific Research (DSR), King Abdulaziz University, Jeddah. The authors, therefore, acknowledge with thanks technical and financial support of DSR.

Received: 9 April 2015 Accepted: 1 September 2015 Published online: 29 September 2015

\section{References}

1. Browder, FE: Nonexpansive nonlinear operators in a Banach space. Proc. Natl. Acad. Sci. USA 54, 1041-1044 (1965)

2. Göhde, D: Zum prinzip der kontraktiven abbildung. Math. Nachr. 30, 251-258 (1965)

3. Kirk, WA: A fixed point theorem for mappings which do not increase distances. Am. Math. Mon. 72, 1004-1006 (1965)

4. Goebel, K, Kirk, WA: Topics in Metric Fixed Point Theory. Cambridge Stud. Adv. Math., vol. 28. Cambridge University Press, Cambridge (1990)

5. Goebel, K, Reich, S: Uniform Convexity, Hyperbolic Geometry, and Nonexpansive Mappings. Dekker, New York (1984)

6. Khamsi, MA, Kirk, WA: An Introduction to Metric Spaces and Fixed Point Theory. Wiley, New York (2001)

7. Ran, ACM, Reurings, MCB: A fixed point theorem in partially ordered sets and some applications to matrix equations. Proc. Am. Math. Soc. 132, 1435-1443 (2004)

8. Nieto, JJ, Rodríguez-López, R: Contractive mapping theorems in partially ordered sets and applications to ordinary differential equations. Order 22, 223-239 (2005)

9. Banach, S: Sur les opérations dans les ensembles abstraits et leurs applications. Fundam. Math. 3, 133-181 (1922)

10. Goebel, K, Kirk, WA: Iteration processes for nonexpansive mappings. Contemp. Math. 21, 115-123 (1983)

11. Beauzamy, B: Introduction to Banach Spaces and Their Geometry. North-Holland, Amsterdam (1985)

12. Borwein, J, Reich, S, Shafrir, I: Krasnoselskii Mann iterations in normed spaces. Can. Math. Bull. 35, 21-28 (1992)

13. Ishikawa, S: Fixed points and iteration of a nonexpansive mapping in a Banach space. Proc. Am. Math. Soc. 59, 65-71 (1976)

14. Krasnoselskii, MA: Two observations about the method of successive approximations. Usp. Mat. Nauk 10, 123-127 (1955)

15. Reich, S: Weak convergence theorems for nonexpansive mappings in Banach spaces. J. Math. Anal. Appl. 67, 274-276 (1979)

16. Reich, S, Shafrir, I: Nonexpansive iterations in hyperbolic spaces. Nonlinear Anal. 15, 537-558 (1990)

17. Opial, Z: Weak convergence of the sequence of successive approximations for nonexpansive mappings. Bull. Am. Math. Soc. 73, 591-597 (1967)

\section{Submit your manuscript to a SpringerOpen ${ }^{\circ}$ journal and benefit from:}

- Convenient online submission

Rigorous peer review

- Immediate publication on acceptance

- Open access: articles freely available online

- High visibility within the field

- Retaining the copyright to your article 